\title{
As epidemias e a memória histórica
}

\author{
https://doi.org/10.21814/uminho.ed.23.9
}

\begin{abstract}
Alexandra Esteves
Alexandra Esteves (ORCID: 0000-0003-0660-9485) é docente de História Contemporânea na Universidade Católica Portuguesa e na Universidade do Minho, sendo investigadora integrada do Lab2PT, unidade de investigação desta última Universidade. A sua atividade investigativa tem sido dedicada a matérias que se inscrevem na área da História Social, designadamente a saúde, a doença, a assistência, a marginalidade, a violência e as prisões, bem como na História do Turismo, incluindo questóes relacionadas com o lazer e as sociabilidades, entre os séculos XVIII e XX.
\end{abstract}




\section{INTRODUÇÃO}

A relação entre a humanidade e a doença tem sido objeto de reflexão em várias áreas do conhecimento. A História, que também se interessa pelo estudo dessa temática, tem a particularidade de mostrar que, em diferentes tempos e lugares, o Homem procurou compreender, explicar e combater as muitas enfermidades com que se tem deparado no decurso da sua existência. Hoje, é reconhecido, e experienciado, o impacto das doenças e das epidemias na vida dos povos e o facto de impulsionarem profundas transformaçóes na sociedade.

$\mathrm{Na}$ Antiguidade, os gregos já manifestavam a sua preocupação com a forma como o ambiente afetava a saúde do ser humano (Berridge \& Gorsky, 2012). Acreditavam que as doenças tinham uma origem mitológica. Aberta a caixa de Pandora, as enfermidades espalharam-se e passaram a acometer os homens, que tiveram que se submeter a Zeus (Ferreira, 2015, p. 556).

Percorrendo a História e chegando ao século XIX, um outro fator é invocado para explicar a doença: as condiçóes de vida das populações. Vários estudos foram realizados com o propósito de perceber de que modo influem no aparecimento e na propagação de enfermidades e de epidemias (Berridge \& Gorsky, 2012). Concluiu-se que, para as prevenir e combater, era necessário mudar comportamentos e investir no melhoramento da situação dos indivíduos, o que requeria mais intervenção do Estado no setor social.

A partir de finais de oitocentos, graças às descobertas de Pasteur e de Koch, entre outros, verifica-se uma maior focalização no indivíduo. Entretanto, o ambiente separa-se da saúde e, já no século XX, em alguns países, aparece associado a projetos ideológicos. Por exemplo, as campanhas antitabágicas levadas a cabo pelo nazismo denotam preocupação com a saúde. Hitler adotou uma retórica médica e a propaganda nazi projetava o médico como um guardião da saúde racial e como um soldado no combate contra a doença (Weindling, 2000). Os bacteriologistas eram elevados à categoria de heróis e o discurso hitleriano associava o tifo aos povos sem pátria, como os ciganos e judeus. A pretensão de exterminar parasitas e controlar doenças levou à nazificação da epidemiologia. Ferdinand Hueppe, um dos mentores da ideologia ariana, com os 
escritos sobre a higiene racial dos gregos, defendia a existência da predisposição racial para a doença e a interferência de fatores rácicos no seu aparecimento, além de advogar a higiene constitucional e a adoção de medidas estatais com vista à promoção de dietas adequadas e do exercício físico (Weindling, 2000).

$\mathrm{Na}$ análise que faz sobre as doenças e as epidemias, o historiador é naturalmente levado a introduzir um terceiro elemento nesta relação algo ziguezagueante, mas possibilitadora de resultados: a sociedade. O conhecimento sobre a doença influenciou a forma como é concebida. Em diversas ocasióes, as elites, os detentores ou os candidatos à conquista do poder não hesitaram em utilizá-la para legitimar argumentos e até como arma de arremesso contra certos grupos, tidos por responsáveis pelo seu surgimento e pela sua disseminação (e.g. os judeus, os pobres, os ciganos e outras minorias).

No âmbito da construção da diferenciação de géneros, é de registar o papel da medicina. Em oitocentos, os médicos esforçam-se para marcar as dissemelhanças entre homens e mulheres, procurando mostrar que estas são inferiores, intelectual e anatomicamente, em relação aos homens, o que justificaria a circunscrição da vivência feminina à esfera doméstica. As características mentais e psicológicas de homens e mulheres resultariam da sua fisionomia, muito particularmente dos seus órgãos sexuais, e não haveria nada a fazer contra esse determinismo, a não ser a assunção de papéis sociais distintos. No discurso médico, a mulher está remetida, essencialmente, à função para a qual o seu corpo tinha sido moldado e estava preparado: a maternidade. Imiscuir-se em domínios tipicamente masculinos, poderiam desgastá-la e torná-la incompetente nas áreas que the eram próprias ou ainda comprometer a sua estabilidade emocional, devido ao aparecimento de doenças do foro mental, ou ainda provocar a esterilidade. Assim, as construções sociais em torno da doença permitiram que esta funcionasse, em determinadas circunstâncias, como instrumento de estigmatização e segregação. Por conseguinte, não pode ser reduzida à sua dimensão natural ou física, mas deve ser contextualizada, apesar das correntes que emergem das descobertas oitocentistas e que a encaram como uma realidade exterior ao ser humano.

As enfermidades sempre foram, e continuam a ser, agentes de miséria, sofrimento e morte. Devem ser perspetivadas como realidades patológicas, mas igualmente como construçốes sociais. Se até há alguns anos atrás, a literatura tendia a excluir esta 
vertente da influência sobre as estruturas sociais ou sobre a dimensão individual do quotidiano, atualmente é consensual o reconhecimento da sua interferência sob o ponto de vista social e cultural. Assim, é inegável que as doenças afetaram as civilizaçốes de diversas formas, não apenas a nível demográfico, mas também a nível social, político, económico e cultural. A arte e a literatura constituem importantes veículos, ainda que menos óbvios, para estudar o(s) impacto(s) que tiveram ao longo do tempo. Foram bloqueadoras de atividade e motivos de inspiração, influenciadoras de contextos mais otimistas ou pessimistas, condicionando movimentos e fazendo do corpo instrumento de comunicação. Paradigmático deste aspeto, e até premonitório, é o quadro do pintor austríaco Egon Schiele, $A$ Familia, que remete para uma família (a sua) que não se concretiza pela morte da esposa e, três dias depois, do seu próprio falecimento, vitimado pela pneumónica. Esta epidemia teve o condão de fechar ciclos, antecipar mudanças e estimular a adoção de novos hábitos e comportamentos, como a prática desportiva e as atividades de lazer ao ar livre. Porém, como afirma J. N. Hays (2009), há uma relação entre as civilizaçóes e as doenças. São múltiplas as doenças e as circunstâncias históricas que atestam esta relação bilateral.

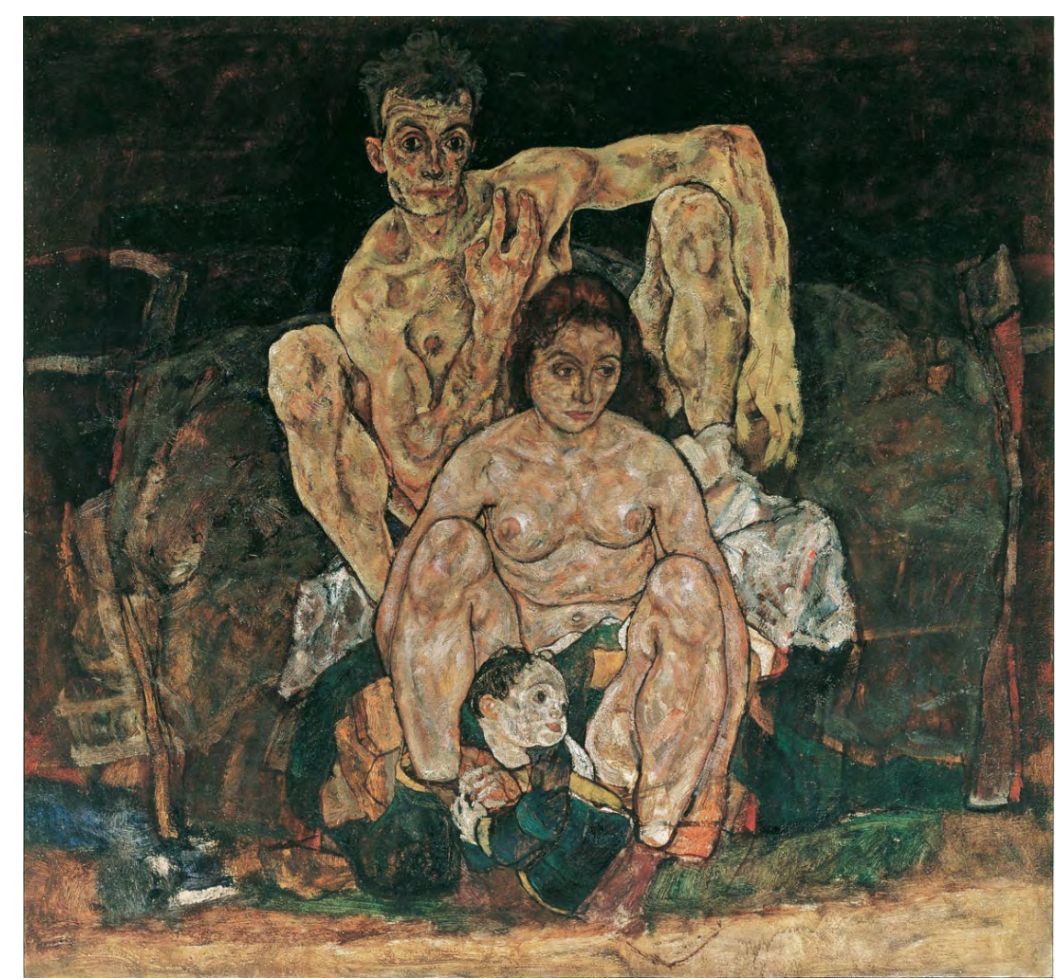

Figura 1. Reprodução da pintura, A Família de Egon Schiele. @WikiCommons. 


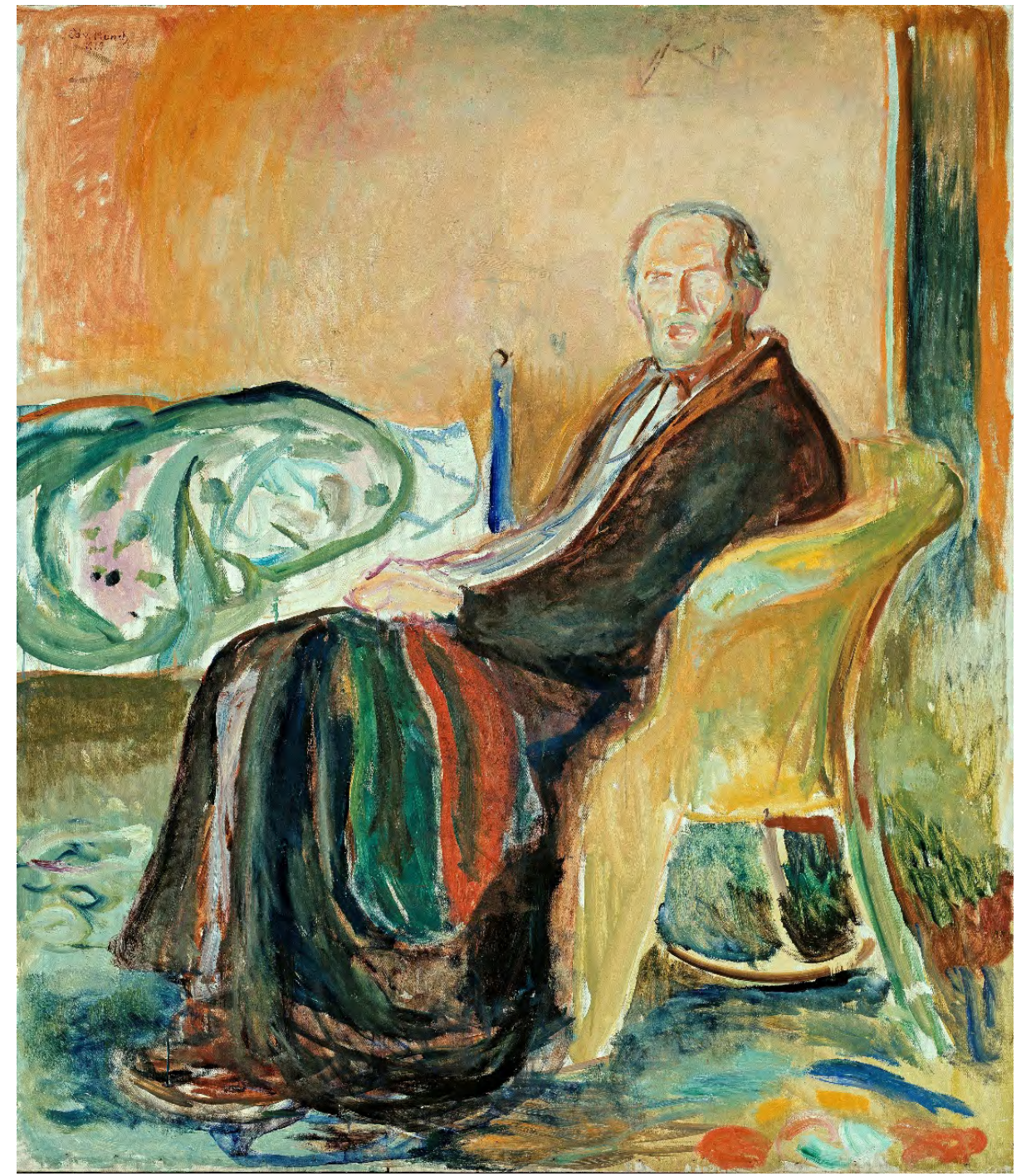

Figura 2. Reprodução do Autorretrato depois da gripe espanbola (1919) de Edvard Munch. @WikiCommons.

Se algumas doenças causavam repulsa e medo, pelos sintomas que exibiam e pela degradação que causavam, como a cólera, que aterrorizou os europeus no século XIX, outras assumiram uma aura romântica, inspirando óperas, peças de teatro e obras literárias, como foi o caso da tuberculose (Snowden, 2020). A dor e a angústia motivadas pelas epidemias tendem, contudo, a ser distintas das advenientes das doenças endémicas ou crónicas. Os seus efeitos são mais devastadores, mesmo em países mais desenvolvidos e sua história é longa. Estão longe de ser uma ameaça controlada ou longínqua, dado que vários fatores contribuem, no tempo corrente, para a sua recorrência, nomeadamente as alterações climáticas, o crescimento demográfico, a globalização e a 
expansão urbana. Habitualmente, a sua disseminação decorre da ação humana, como sucede, por exemplo, nos conflitos armados. Tifo, malária, febre tifoide e sífilis faziam parte dos campos de batalha, a partir dos quais chegavam às cidades (Snowden, 2020).

As moléstias que têm atormentado a humanidade ao longo do tempo foram mudando e refletem o modo de vida das populaçóes, os seus comportamentos, o seu modo de vida, os seus hábitos alimentares e de consumo, a sua relação com a natureza, e, normalmente, têm impacto nas suas existências, interferindo nas formas de organização familiar, social e económica. Não se trata de entidades fixas, mas, pelo contrário, variam e têm capacidade de adaptação. Daqui se infere a importância de conhecer os seus contextos (Cohn, 2018). Além do mais, movimentam-se com as pessoas, refletem a sua capacidade de circulação e até se globalizam, sem se deterem nas fronteiras.

Durante a maior parte do seu processo evolutivo, os seres humanos viveram em pequenas comunidades, contactando com elementos patogénicos, através dos ataques dos insetos, do consumo de carne contaminada, do contacto com os animais domésticos e de trabalho. À medida que se instalaram em climas mais moderados, foram-se afastando de certas doenças. Todavia, a sedentarização favoreceu o aparecimento de outras, como a gripe, a varíola ou o sarampo (Stearns\&Koella, 2010).

Normalmente, as epidemias são ocasionadas por um agente patogénico, um vírus ou um parasita, que, quando assume um caráter infectocontagioso, pode originar grandes surtos pestíferos. Podem ganhar contornos endémicos, quando a doença se circunscreve a uma região, e epidémicos quando alastra de forma rápida e generalizada, ou pandémicos, quando se globaliza. A história mostra que algumas epidemias surgem da mutação de agentes (caso da influenza, vírus causador da gripe) ou do surgimento de novos vírus, como foi o caso do responsável pelo ébola ou pelo HIV/SIDA.

A preocupação com e em controlar a doença e os surtos epidémicos sempre acompanhou o Homem. Desde a Idade Moderna, os países têm-se mostrado empenhados em evitar a sua ocorrência ou em minorar os seus efeitos. Nesse sentido, diversas medidas têm sido tomadas, nem sempre bem aceites pela população: quarentenas; reforço do auxílio médico; isolamento de contaminados; intervenções sanitárias nos espaços públicos, entre outras. Com o mesmo objetivo, à medida que caminhamos para a 
contemporaneidade, foram adotadas estratégias que propiciaram avanços no domínio da saúde pública, que se materializaram, nomeadamente, no desenvolvimento do sanitarismo urbano e no incremento de planos de vacinação.

Além da questão humana, os estados consideravam que o combate à doença era fundamental, dado o valor económico e militar das suas populaçôes. Assim, seriam tanto mais fortes quanto maior fosse o número de efetivos populacionais. Importava, por isso, investir em medidas que acautelassem a saúde pública. Por outro lado, a partir do século XVI, com as expansóes europeias, inicia-se a economia global, o que fez com que muitos agentes patogénicos do Novo Mundo chegassem à Europa e os europeus levassem muitas doenças para os territórios descobertos. Vários autores, como Alfred Crosby, utilizam a expressão "imperialismo ecológico" e avançam com a ideia, não consensual, de que os impérios europeus do século XVI, particularmente o espanhol, se construíram à custa da disseminação de doenças, como a varíola e o tifo. A revolução dos transportes no século XIX, com o caminho-de-ferro e o barco a vapor, facilitou ainda mais a sua propagação. Assim, se explica a saída da cólera do nicho indiano e o rápido alastramento da peste bubónica, que, em finais do século XIX, da China chegou à Índia e daqui rapidamente alcançou o Mediterrâneo e, em 1899, a cidade do Porto.

Coloca-se, então, a seguinte questão: qual o papel da história neste processo? A história pretende conhecer a forma como as pessoas entenderam e percecionaram as doenças no passado e analisar as suas consequências sob diversos prismas (económico, social, cultural, político e até mental).

\section{AS EPIDEMIAS}

Antes de nos debruçarmos sobre as epidemias, a história e a memória, convirá esclarecer o conceito de epidemia, que, vulgarmente, é entendida como 'Doença que, numa localidade ou região, ataca simultaneamente muitas pessoas"r.

1 “epidemia”, in Dicionário Priberam da Língua Portuguesa [em linha], 2008-2020, https://dicionario.priberam.org/epidemia [consultado em 19-06-2020]. 
Poderíamos trazer outras definições, no entanto, apesar de diferentes, encontraríamos várias características comuns: o seu caráter temporário, a circunscrição territorial, a morbilidade e a mortalidade acima do usual. Há doenças endémicas, epidémicas e pandémicas. A designação "pandemia” só começou a ser utilizada no século XX. O uso da palavra "epidemia" não está isenta de uma certa ambiguidade, pois há doenças que marcaram o passado e são deveras difíceis de catalogar. Trata-se de doenças endémicas que acompanham a humanidade desde há séculos, mas que, por razões ambientais ou outras, têm uma maior incidência, atingindo picos que lhes dão uma proporção epidémica. A este propósito, são de mencionar os exemplos do tifo e da tuberculose.

A tuberculose é conhecida desde há milhares de anos, tendo sido identificada em múmias egípcias. Ao longo do tempo, a sua denominação foi-se alterando: escrófulas, tísica. Mas foi no século XIX que alcançou uma dimensão pestífera, que justificou a designação que então the foi atribuída: "peste branca". Com a industrialização a incentivar homens e mulheres a partirem para as cidades, estas transformam-se em verdadeiros antros de doenças. Amontados em bairros periféricos e insalubres, junto a fábricas e lixeiras, condenados a sobreviver com magros salários, incapazes de satisfazer necessidades básicas, os operários serão as principais vítimas da enfermidade. $\mathrm{O}$ bacilo de Koch tinha, no entanto, a particularidade de não discriminar classes, não distinguindo o casebre do palácio, embora tivesse preferência por corpos debilitados, cansados e consumidos. As proporções que a tuberculose atingiu em oitocentos exigiu dos estados a tomada de medidas para a combater e Portugal não foi exceção. Assim, em 1853, na cidade do Funchal, surgiu o primeiro sanatório português. Nos finais do século, em 1894, foi instituída a declaração obrigatória da tísica e, no ano seguinte, teve lugar o primeiro grande congresso sobre a doença. Também nesta década foi organizada uma comissão para estudar a melhor resposta hospitalar para os tuberculosos.

No âmbito das medidas destinadas a combater a "doença do peito", Miguel Bombarda propôs a fundação da Liga Nacional contra a Tuberculose, com núcleos espalhados pelo país. Em 1899, por iniciativa da rainha D. Amélia, foi constituída a Assistência Nacional aos Tuberculosos (ANT), tendo como objetivos a criação de instituiçôes para tísicos, a construção de sanatórios para os tuberculosos curáveis e de hospitais marítimos para crianças. A ANT tinha duas sucursais, uma no Porto e outra em 
Coimbra, e 13 delegaçôes. Entre as suas realizações, destacam-se a fundação, em 1900, do Sanatório Marítimo do Outão e, em 1902, do Sanatório Marítimo de Carcavelos.

Não havia consenso entre as autoridades sanitárias portuguesas quanto à melhor forma de lutar contra a tuberculose: enquanto uns apostavam na construção de sanatórios, outros elegiam a criação de dispensários. Impressionado com a experiência francesa, António de Lencastre pugnou, com sucesso, pela segunda hipótese, por entender que os dispensários permitiam uma intervenção mais precoce e eficaz sobre a doença e o paciente. Os sanatórios, por seu lado, foram-se transformando em antecâmaras da morte, aos quais os pacientes acorriam, muitas vezes já em estado terminal (Ferreira, 2005, p. 73). O primeiro dispensário antituberculoso foi aberto em Lisboa, em 1901. Por iniciativa da Associação Nacional aos Tuberculosos, outros foram criados em diversos lugares. Além da atividade orientada para a prevenção e tratamento das doenças infeciosas, nomeadamente através do apoio domiciliário aos enfermos e da distribuição de leite e de substâncias medicamentosas, os dispensários investiam também na vertente educativa. Assim, ao facultativo não competia apenas informar o paciente sobre o seu estado de saúde e prescrever a terapia adequada, mas também corrigir os comportamentos considerados inadequados. Deste modo, estas instituições cumpriam uma tripla função: prevenir, tratar e educar.

Na primeira metade do século XX, no âmbito do combate à tuberculose, várias campanhas de sensibilização foram somadas à fundação de estabelecimentos específicos, tendo em vista a alteração de hábitos e comportamentos. Afigura-se oportuno referir que, em 2020, apesar dos avanços conseguidos, continua a ser uma das doenças que mais mata no mundo, sobretudo nos países mais pobres e onde as desigualdades sociais são mais profundas.

O tifo, outra enfermidade que também tem acompanhando a humanidade ao longo dos tempos, atingiu, em algumas épocas, picos inesperados. Foi o que sucedeu quando entrou na Europa pelo sul da Espanha, em 1489. Tornou-se frequente nas cadeias e em cenários de guerra, por se propagar facilmente em ambientes onde escasseiam as condiçôes higiénicas e sanitárias. Em 1624, mais de 10 mil habitantes de Amesterdão morreram. A doença chegou ao século XX e continuou a preocupar as autoridades de saúde. 
A primeira epidemia sobre a qual existem fontes foi de peste. Teve lugar em 712 a.C. e vitimou o exército assírio de Senaqueribe, durante o cerco a Jerusalém (Ferreira, 2015, p. 557). Há referências documentais a várias epidemias de grandes proporçóes que aconteceram na Antiguidade Clássica. Destacam-se as pestes de Xerxes (480-420 a.C.), descrita por Heródoto, e de Atenas, contada por Tucídides na sua obra sobre a Guerra do Peloponeso, focando as suas consequências sociais e até psicológicas (Kohn, 1995, p. 260). Sobre o seu percurso, presume-se que, a partir da Etiópia, se terá estendido ao Egipto e à Líbia, alcançando a Pérsia e daqui à cidade-estado de Atenas. Tucídides descreve-a como uma doença altamente contagiosa, o que terá levado os atenienses a recusarem visitar-se uns aos outros. Estudos recentes apontam para a probabilidade de se ter tratado de um surto de febre tifoide, que se prolongou no tempo, provocando um grande número de vítimas, e que terá marcado o início do declínio daquela cidade-estado.

Prosseguindo no caminho da História, verificamos que o Império Romano foi atingido por vários surtos epidémicos, situação que decorria da sua dimensão e composição, bem como da circulação de pessoas e bens pelas diversas regiôes do Império. Entre as mais severas, destaca-se a peste antonina, com início em 165 e que se prolongou até ao ano 180. Galeno conheceu a peste e relatou os seus sintomas, que terá sido de varíola, enfermidade que também acompanhará a Humanidade até à sua erradicação, já na segunda metade do século XX. Aponta-se, embora não seja consensual, a Babilónia como o lugar de origem, tendo alastrado, primeiramente, pela parte oriental do Império, percorrendo depois várias províncias, até chegar aos povos germânicos do outro lado do limes. No entanto, segundo outras perspetivas, terá começado no Egito, espalhando-se por vários lugares até chegar a Roma, onde a morbilidade foi maior, o que não é de estranhar, se se tiver em conta o elevado número de habitantes que a cidade albergava. Terá vitimado entre três milhões e meio e cinco milhóes de pessoas, matando mais nos centros urbanos e nos acampamentos militares. Vitimou ricos e pobres, e o próprio imperador, Marco Aurélio, não saiu incólume.

Gregos e romanos tinham uma visão híbrida sobre a forma de ultrapassar a doença, recorrendo ao sobrenatural. Os primeiros acumularam um legado de outras culturas e tradiçóes, tornando incerta a fronteira entre o natural e o sobrenatural. Aquando 
da peste antonina, os romanos voltaram-se para os deuses para superar o sofrimento e a morte, e culparam os cristãos pela sua ocorrência. O desespero fez proliferar charlatães e curandeiros. O Cristianismo que, entretanto, penetrara na civilização romana, traz uma visão diferente da saúde e da doença. São várias as referências a enfermidades no Antigo Testamento, sendo apresentadas sob o ponto de vista do sobrenatural, com uma ligação a Deus, que atua como forma de castigar os erros humanos. Esta leitura conduzirá à ideia da enfermidade como punição pelos pecados cometidos. O período de difusão do Cristianismo coincidiu com algumas epidemias, como a peste de Cipriano, ocorrida no século III, admitindo-se a hipótese de se ter tratado de um surto de varíola ou sarampo.

Já após a queda do Império Romano do Ocidente, na Alta Idade Média, o mundo ocidental foi afetado por um terrível surto de peste, a peste justiniana, assim chamada por ter surgido no tempo do imperador Justiniano I. Proveniente do Oriente, alcançou o Mediterrâneo, regióes de Itália e França, através da atividade comercial, envolvendo assim o Ocidente e o Oriente, entre os anos 541 e 750 (Kohn, 1995, p. 254). Terá dizimado entre 20 e 50 milhóes de vítimas e os seus efeitos ajudaram a consolidar a passagem do mundo antigo para a medievalidade.

Depois desta calamidade, a Alta Idade Média ficou afastada de epidemias até ao século XIV, embora tenha sido, como os outros períodos do tempo medievo, fortemente afetada por um conjunto de enfermidades que resultavam das próprias condiçôes de vida das populaçóes, designadamente da grande proximidade aos animais, das precárias condiçôes de higiene e habitação, bem como da composição das dietas alimentares, caracterizadas pela ausência de proteínas, ferro e certas vitaminas. Há também outros fatores que podem ser invocados para justificar um certo estancamento dos surtos epidémicos, como o facto de a Europa ser um espaço essencialmente rural, onde as pessoas tinham dificuldade e até medo de viajar, e a diminuição acentuada da atividade comercial, que se verificou em algumas partes, o que também ocasionou a redução da circulação de gente e de mercadorias e, consequentemente, a circunscrição das doenças a determinados territórios.

A partir de finais do século $\mathrm{X}$, a atividade mercantil desponta e consolida-se em algumas regiões; os ofícios ganham dinamismo; a população e as cidades crescem; a 
agricultura desenvolve-se e arroteiam-se terras para alargar as áreas de cultivo; a produção aumenta. Ora, com o desenvolvimento surgem também condições propícias à deflagração de crises epidémicas. As urbes medievais eram espaços desordenados, com ruas estreitas e escuras, por onde circulavam homens e animais, onde abundavam ratos e pulgas, o lixo era despejado pela janela e a relação com a água era distante Era este o cenário da Europa, quando foi atingida, em 1347, pela peste negra, uma epidemia que arrasou cidades inteiras e terá matado entre $30 \%$ a $60 \%$ da população deste continente, embora alguns territórios tenham sido mais fustigados do que outros. As cidades italianas foram das primeiras a serem tomadas pela doença. No ano seguinte, estava no norte da Península Itálica e acaba por atingir a Espanha, França, Inglaterra Suíça e Hungria. Em 1349, chega à Escócia, à Irlanda, aos Países Baixos, à Noruega, à Suécia e à Rússia.

No rol das medidas sugeridas para debelar a peste, constavam o estabelecimento de quarentenas, cordões sanitários e lazaretos; a utilização de máscaras; o isolamento das casas dos doentes e o reforço das medidas de salubridade; a intensificação da limpeza dos espaços públicos; o rápido enterramento dos cadáveres; acendimento de fogueiras e queima de ervas aromáticas para purificar o ar.

Como noutras ocasiôes, houve a necessidade de encontrar um culpado! Neste caso, o ónus da culpa recaiu sobre os judeus. Como lavavam frequentemente as mãos antes das refeiçóes e usavam a água dos rios, foram acusados de envenenar os poços. Esta acusação, a que se juntaram outros pretextos, desencadearam perseguições, que em algumas regióes europeias se traduziram em autênticos massacres, com milhares de judeus a serem queimados vivos.

A Europa recuperará desta calamidade, mas os ratos e as pulgas permaneceram nas cidades e, ao longo da Idade Moderna, a peste negra regressará ao continente europeu com alguma frequência, embora com intensidade desigual, continuando a matar.

Antes de passar à época seguinte, importa refletir sobre as mudanças provocadas pela peste, uma das pandemias mais mortíferas que assolou o Velho Continente. Convirá notar que ocorreu numa Europa cristã, que a encarou como uma punição, e, neste quadro, assistiu-se a um conjunto de açôes que visavam, de certo modo, minimizar o fardo do castigo. Organizaram-se procissóes de flagelantes; elegeram-se novos santos e 
mártires; a arte refletiu o espectro da morte. Com o caos e a desordem, multiplicaram-se os comportamentos marginais, intensificou-se a violência e a criminalidade.

O ciclo da peste só se fechará com a terceira pandemia, que ocorre já no século XIX, estimando-se que tenha provocado 13 milhões de vítimas (Harrison, 2009, p. 128). Nesta época, o bacilo da epidemia habitava em ratos de Yunnan, no sul da China. Em 1894, a peste chega a Hong Kong. Daqui alcança a Índia e, rapidamente, espalha-se por cidades portuárias e importantes centros comerciais, passando a circular com os barcos. Chegou ao Mediterrâneo e, em 1899, à cidade do Porto. O continente americano não será poupado, com várias cidades a serem afetadas, como São Francisco, Buenos Aires e Rio de Janeiro. O combate faz-se agora com recurso a novas medidas de saúde pública, que incluem a exterminação dos ratos.

Antes de chegarmos à contemporaneidade, outras enfermidades atormentaram as populaçôes entre os séculos XVI e XVIII. Trata-se de um período marcado pela globalização das epidemias, para a qual muito contribuíram as expansões europeias. Mas é, igualmente, uma fase da História onde se adensam as preocupações com o sanitarismo, apostando-se na higienização das cidades, na construção de cemitérios e na edificação de novas estruturas hospitalares.

Fruto do contacto com novas terras e com outras gentes, os europeus acreditavam que a sífilis provinha do Novo Mundo, moléstia que se torna endémica na Europa a partir do século XVI, onde já existia. Se, nos dias de hoje, a questão da sífilis se pode considerar esclarecida, o mesmo não se pode dizer sobre o tifo, que chega à Europa no século XV e onde se mantinha ainda no século XX. Entre as enfermidades que os europeus transportaram para a América, com efeitos devastadores, sobressaem a varíola, a escarlatina, a peste, o sarampo e a gripe.

Além da globalização de certas doenças e da ocorrência de surtos epidémicos que, rapidamente, vitimavam um número considerável de pessoas, o europeu moderno convivia com outras moléstias que, diariamente, colocavam a sua vida em perigo e impediam que muitas crianças alcançassem a idade adulta. Disenteria, difteria, malária, ergotismo, sarampo, garrotilho e coqueluche constam da lista das ameaças. Algumas mantêm-se até hoje, como a febre-amarela, que afetou Portugal e, com particular 
severidade, a cidade de Lisboa, nos séculos XVIII e XIX; outras só atingiram, e de modo esporádico, algumas regióes da Europa. O suor inglês, por exemplo, afetou o norte da Europa no século XVI (entre 1485 e 1551). Passou a ser considerado um mal que atingia os países protestantes, dado que os países católicos (Portugal, Espanha, Itália e França) foram poupados. A doença permanece até hoje como um enigma.

Chegados ao século XIX, os progressos nos transportes encurtam as distâncias e possibilitam que as pessoas circulem mais rapidamente e de forma mais confortável. Ora, as movimentações de pessoas e de mercadorias são acompanhadas por agentes responsáveis por doenças que acabam por ganhar proporçôes epidémicas (e.g. cólera). Além disso, assiste-se a uma espécie de "europeização do mundo", com vários países a lançar-se à conquista de regióes que não integram os "velhos impérios" de Portugal, Espanha, França, Holanda e Inglaterra. Alemães, italianos e belgas também entram na competição. Os alvos são os continentes asiático e africano, sobretudo este último. Há uma verdadeira corrida rumo a África, impulsionada por opiniôes públicas ávidas de expansão territorial, com líderes políticos que ambicionam construir impérios que tragam dividendos. As colónias são territórios abastecedores de matérias-primas e mercados para escoar a produção industrial. É neste contexto que se enquadram as viagens de exploração, que, mais do que expedições científicas, serviam para legitimar a posse de terras e domínios, que culminarão na Conferência de Berlim em 1884-1885 e no espartilhamento de África. Ao penetrar na selva africana e em regióes inóspitas para o ser humano, o europeu entra em contacto com novos microrganismos. Tal como tinha sucedido séculos antes, também agora muitos dos que regressaram da selva africana transportaram agentes para os países de origem e expuseram as populaçóes locais a doenças, como a varíola (Crosby, 2015).

Em 1817, a cólera abandona o nicho indiano e alcança a Europa nesse ano. A sua propagação coincide com a presença inglesa no continente asiático. A doença irá deslocar-se com os exércitos e seguirá as rotas comerciais. Foi uma enfermidade que marcou o século XIX e que obrigou os estados a fazerem reformas no campo da saúde pública. Foi amplamente escrutinada pela imprensa da época, o que permitiu que a população fosse informada sobre o seu desenvolvimento. Portugal conheceu essa realidade em contexto de guerra civil e, a longo do século XIX, houve vários surtos. Quando 
chegou a cólera, o país já se debatia com outras moléstias, designadamente a tuberculose, que deixa de ser perspetivada como uma doença do indivíduo e passa a ser considerada um problema de saúde pública. O tifo, a febre tifoide e a varíola também continuaram a grassar, por vezes de forma epidémica, ao longo desta centúria.

A malária, conhecida por sezões ou sezonismo, também marca presença em Portugal, neste tempo. O avanço do homem sobre o continente africano no século XIX ditou a sua expansão, acabando por chegar também à América, onde permanece, com caráter endémico, até à atualidade. $\mathrm{O}$ mundo não se livrou da malária, pelo contrário. A partir da década de 70 do século XX, regressa em força com cerca de 7 milhóes de casos. Nos finais do século passado e nos inícios do novo milénio, temia-se o seu alastramento, devido, essencialmente, às alteraçôes climáticas e ao aquecimento do planeta. O aumento das temperaturas, resultante destes dois fatores, favorece a disseminação do mosquito responsável pela doença em regióes que lhe eram estranhas. Por outro lado, alguns países não têm sido capazes de aplicar as medidas indispensáveis para combater o agente responsável pela doença.

Outra enfermidade que não conhece limites temporais ou barreiras geográficas é a gripe. Acompanha o homem desde há milhares de anos, mas nem por isso tem merecido especial atenção dos historiadores (Lindemann, 2002, p. 60). A exceção tem sido a gripe espanhola. Em Portugal, desde a Idade Média que são conhecidos surtos, que se repetiram na época seguinte e na contemporaneidade. A primeira grande pandemia de gripe terá sucedido em 1580, fazendo-se sentir na Ásia, na Europa e em África (Beveridge, 1991). No século seguinte, assim como no século XVIII, vários surtos assolaram a Europa, sendo que a última grande epidemia ocorreu em 1782 e, mais uma vez, percorreu continentes.

No século XIX, ocorre a epidemia de gripe russa. Não há acordo sobre a sua origem: uns apontam a Sibéria, outros o Turquemenistão como territórios onde apareceram os primeiros casos. Depressa se propagou por toda a Europa, chegando ao continente americano, às cidades portuárias de Boston, Nova Iorque, Baltimore, Nova Orleães e Filadélfia. Não se ficou por aqui e acabou por chegar à Austrália e à Nova Zelândia. Atacou, indistintamente, ricos e pobres, e julga-se que terá vitimado um milhão de indivíduos, embora este número também seja contestado. A doença atingiu Portugal 
nos anos de 1889 e 1890. Em dezembro de 1889, chegou à cidade de Lisboa, onde se estima que metade da população foi atacada (Soares, 1892). Daqui seguiu para o Norte do país. Os homens foram mais atingidos do que as mulheres e as crianças com menos de dois anos de idade escaparam à doença, ou foram tocadas com gravidade benigna.

A gripe russa causou inúmeros danos, designadamente nos planos demográfico, social, político e económico, mas também favoreceu o desenvolvimento de diversas áreas, como a estatística, e estimulou o interesse pela investigação da enfermidade, levando à descoberta do bacillus influenza e bacilo de Pfeiffer (Garcia Ferreiro, 2018). Os países demoraram algum tempo a reagir, até pela dificuldade em estabelecer um diagnóstico preciso. Assim se explica que a medicina convencional falhasse e que a população se voltasse para curas pretensamente milagrosas e salvadoras. Na época, para combater o mal, recomendava-se resguardo, descanso e isolamento.

Os surtos de gripe foram habituais ao longo da História, vitimando, geralmente, os mais vulneráveis. A pneumónica, ou gripe espanhola, foi a maior pandemia mundial de gripe. Os estudos mais recentes apontam para entre 50 e 100 milhóes de óbitos, mas há quem defenda que a barreira dos 100 milhóes de mortos terá sido ultrapassada. Uma das características que causou mais impacto foi o facto de ter atacado sobretudo a população jovem e saudável, na faixa etária dos 20 aos 40 anos, em vez da mais idosa e debilitada. Há quem sustente que muitos idosos de 1918, vítimas da gripe de 1890, teriam adquirido uma imunidade parcial que os defendeu contra as formas mais agressivas da doença. Todavia, esta é uma questão que permanece sem resposta conclusiva.

A origem geográfica da gripe espanhola é discutível. A versão mais consensual defende que começou nos aquartelamentos do exército dos Estados Unidos, no Kansas, e foi levada depois para França pelo Corpo Expedicionário Americano (Spinney, 2018). No entanto, há quem advogue a origem europeia (Oxford, 2000), em França, ainda em 1916, atribuindo aos soldados ingleses já contaminados o seu transporte para os Estados Unidos. Também há autores que situam o seu início na China, tendo chegado ao continente europeu com trabalhadores chineses. Afinal, não há provas concludentes que possam confirmar em qual dos lugares apareceu pela primeira vez. 
Também não há consenso quanto ao número de surtos, se bem que, usualmente, se admita que houve três. Em março surgem os primeiros casos nos Estados Unidos, em maio está na Alemanha, no norte de África e na Índia; em junho, atinge a China e, em julho, a Austrália. No verão, a doença permanece na Europa. Na altura, Mustafa Kemal Ataturk, fundador e primeiro Presidente da República da Turquia, ficou retido em Viena de Áustria por causa da epidemia (Spinney, 2018; Crosby, 2003). O aparecimento do segundo surto, em agosto, fez-se notar em três pontos do Atlântico, acabando por alastrar ao interior dos três continentes: Freetown (Serra Leoa); Boston (Estados Unidos) e Brest (França). No mês seguinte, já estava no norte da Ásia e na Índia e, em outubro, na China. Foi o mais violento dos surtos e o que causou o maior número de vítimas. Regressa no início do ano seguinte, mas de forma mais benigna. No entanto, há evidências da ocorrência de uma quarta vaga em Portugal, no outono/inverno de 1920 e 1921, que se terá manifestado sobretudo nas cidades de Braga e Guimarães (Esteves, 2020).

Portugal foi atingido pela pandemia em maio de 1918, quando foram identificados os primeiros casos em trabalhadores agrícolas que regressaram do país vizinho, sobretudo de Badajoz e de Olivença, pela fronteira alentejana. Importa esclarecer que a designação "gripe espanhola" não significa que a doença tenha a sua origem em Espanha, mas deve-se ao facto de as notícias dessa gripe letal chegarem a todo o mundo através da imprensa espanhola, livre de censura, ao contrário do que acontecia em grande parte dos países europeus, incluindo Portugal. Vivia-se o último ano da Primeira Guerra Mundial e temia-se o impacto que a epidemia poderia ter no desenrolar do conflito e o alarmismo que podia causar nas tropas e na população civil. É de salientar que uma das fontes para estudar a pandemia é precisamente a imprensa (Esteves, 2019; Almeida, 2012). Representa um importante repositório de memórias, dado que nos permitem analisar a forma como as populações experienciavam as epidemias, bem como aceder a informaçôes relevantes sobre o seu desenvolvimento, entre muitos outros aspetos. São os jornais da época que nos permitem conhecer, hoje, a tomada de consciência das populaçóes sobre a gravidade da situação que estavam a viver. No jornal $O$ Algarve, a 10 de novembro de 1918, no pico da pandemia, escreveu-se: "Desapareceu o pavor da guerra; já não se choram os nossos compatriotas 
em armas ou nas prisões inimigas! Os lutos da guerra são muito benignos perante os lutos da gripe pneumónica”2.

No entanto, é preciso atender aos condicionalismos que influenciam esta fonte. Um deles é a censura. Aquando do primeiro surto, as notícias escasseiam e são muito lacónicas. Mesmo quando tem lugar a segunda vaga, os jornais nacionais de maior circulação não lhe dão grande importância, focando-se, essencialmente, no desenvolvimento do conflito que então assolava o mundo. São publicadas medidas da Direção-Geral da Saúde, vai-se fazendo o ponto de situação do estado sanitário do país, são divulgados alguns tratamentos e substâncias medicamentosas para tratar a epidemia e publicitam-se soluções tidas como inovadoras. No entanto, na imprensa local e regional, o volume de notícias é maior e é dado mais destaque à pandemia.

Além da guarda de informação sobre a gripe espanhola, que pode ser extremamente útil para quem se dispuser a estudá-la, os jornais desempenharam uma importante função na época, informando e consciencializando a população sobre o tempo que estava a viver. Convirá notar que, quando a doença apareceu, a população encarou-a como um acontecimento localizado e passageiro, não se apercebendo da sua real dimensão, e até lhe foram atribuídas designações variadas, conotadas com animosidades latentes entre povos ou ideologias. Assim, para os polacos era a "gripe bolchevique", para os senegaleses era a "gripe brasileira" e para os brasileiros tratava-se da "gripe alemã”. Importa, ainda, salientar que, apesar do elevado índice de analfabetismo que então se registava em Portugal, era prática habitual a leitura pública dos jornais, em voz alta, em cafés e tabernas.

Tal como sucedeu em Espanha e em Itália, por exemplo, também em Portugal houve alguma hesitação inicial no diagnóstico da pneumónica. No entanto, Ricardo Jorge, então Diretor-Geral da Saúde, não teve dúvidas em identificá-la como sendo a epidemia que já grassava em Espanha. Embora não se possa rotular Portugal como país atrasado em matéria de legislação sanitária, a resposta à doença foi condicionada por diversos fatores, designadamente a insuficiência de médicos e os hábitos e costumes da população, muito arreigados e difíceis de alterar, que contrariavam as regras básicas de

2 O Algarve. Seminário Independente. 10 de novembro de 1018, oo 355. 
higiene. Estas fragilidades ficaram patentes na segunda vaga, que partiu de um quartel militar de Vila Nova de Gaia, quando soldados infetados receberam licença para regressar às suas casas e acabaram por espalhar a doença.

Ao mesmo tempo que a pneumónica se disseminava, outras doenças (varíola e tifo) já grassavam de forma violenta no Norte do país, havendo mesmo zonas onde estas três epidemias coincidiram (Esteves, 2019). A pandemia terá causado a morte a $60 \mathrm{mil}$ pessoas, embora alguns investigadores admitam que o número de óbitos terá chegado aos 100 mil. Algumas regióes terão perdido $10 \%$ da sua população! O alastramento da doença foi facilitado pelas aglomerações de pessoas nas fábricas, nas igrejas e nos transportes públicos. Era, ainda, o tempo de regressar a casa das estâncias termais e balneares e de começar as colheitas! No dia 27 de setembro de 1918, Ricardo Jorge transmitiu as primeiras orientações respeitantes à hospitalização dos doentes, à higiene pública $\mathrm{e}$ individual, à assistência médica e ao apoio aos doentes pobres.

Do que não há dúvidas é que o número de óbitos em Portugal aumentou de forma considerável no ano de 1918, conforme se pode ver no gráfico 1.

Gráfico 1 - Número de óbitos registados em Portugal (1915-1919).

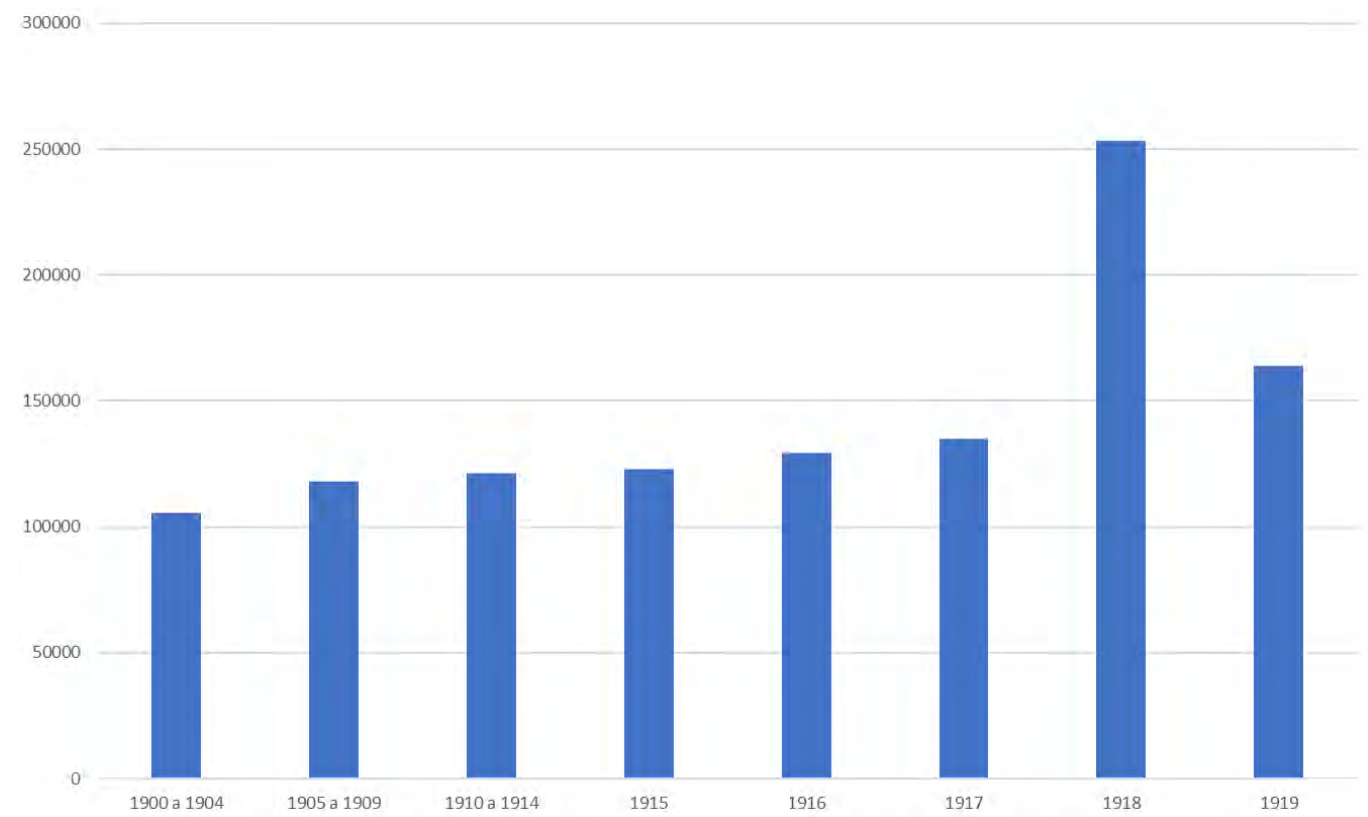

Fonte: INE, Anuário Estatístico de Portugal, Demografia, 1919. 
A instabilidade política e a agitação social que se verificavam em Portugal complicavam ainda mais a resposta à pneumónica. $O$ desconhecimento das especificidades da enfermidade também facilitou a sua disseminação. Os primeiros sinais da pandemia eram muito ligeiros, sendo considerada uma gripe banal, como havia todos os anos, e não foi imposto o isolamento dos infetados. Aliás, Ricardo Jorge não defendia a proibição de feiras, festas e romarias, pois receava o impacto negativo que essa medida causaria num país já muito debilitado e o alarmismo que podia gerar na população. Todavia, nos meses de outubro e novembro, quando foi atingido o pico da pandemia, o país praticamente paralisou. Nesta fase, os ajuntamentos já eram desaconselhados; foi reforçada a limpeza dos espaços públicos; procurava-se identificar todos os doentes falecidos devido à pneumónica para desinfetar as suas casas; cafés, salas de espetáculo e clubes foram encerrados. Tudo para combater o avanço da doença, que não dava mostras de abrandar no fatídico inverno de 1918.

Os hospitais rapidamente esgotaram a sua capacidade, até porque muitos não tinham mais de 10 camas. Houve, então, necessidade de recorrer a outras estruturas, como escolas e conventos, e improvisar hospitais. Muitos médicos não resistiram à doença e, na ausência de assistência hospitalar, as populações foram apoiadas pelas delegaçôes da Cruz Vermelha. Além de cuidar dos vivos, também foi necessário tomar precauçốes com os mortos, cujos corpos se amontavam nas morgues dos hospitais, dada a impossibilidade de cumprir a norma que impunha o sepultamento dos cadáveres nas 24 horas subsequentes ao óbito. Acontecia ficarem dois a três dias a aguardar a realização do funeral, não apenas por serem em elevado número, mas também por haver coveiros que, temendo o contágio, se recusavam a enterrar as vítimas da doença. Abriram-se valas comuns, os esquifes foram vendidos a preços mais acessíveis e os funerais noturnos foram autorizados. A constância da morte levou a que até os sinos deixassem de tocar a defunto!

A pandemia foi experienciada de diferentes modos: uns encararam-na como um castigo divino e, na busca de clemência e de proteção, voltaram-se para Deus e encomendaram missas, fizeram promessas e organizaram procissóes; outros, mais preocupados em encontrar um responsável pelo que estava acontecer, culpavam os comportamentos desregrados e amorais dos pobres, ou as autoridades sanitárias por não serem capazes 
de debelar a doença que ceifava a vida dos mais jovens. As igrejas também fecharam, as missas deixaram de se realizar, as procissóes, os cortejos fúnebres foram proibidos e a população deixou de poder chorar os seus mortos. Finalmente, chegou a altura de cuidar dos sobreviventes, em particular dos órfãos da pneumónica, para os quais foram criados orfanatos, bem como das viúvas e daqueles que viram praticamente toda a família partir e ficaram sós.

Os médicos portugueses atribuíram diversas particularidades à pneumónica: a elevada contagiosidade, a rapidez da propagação, a imprevisibilidade, o caráter pandémico e ondulatório, a evolução condicionada pela presença de outras enfermidades, como a tuberculose, e risco acrescido que representava para as mulheres grávidas. Escreveram sobre a profilaxia e o tratamento mais adequados, apresentando, entre outras, as seguintes medidas e sugestôes: isolamento dos enfermos para evitar o contágio; hospitalização dos infetados; arredamento de aglomerados de pessoas; evitar fadigas desnecessárias e constipaçóes, por debilitarem o corpo e dificultarem a luta contra a doença; usar substâncias medicamentosas destinadas a outras enfermidades. Entendiam, ainda, que o único método eficaz para combater a doença seria a vacina: “(...) são o processo do futuro, o único eficaz quando aplicado em grande escala”. (Costa, 1920, p. 117)

Atendendo à dimensão catastrófica da pandemia, à consciência da sua gravidade e à dor causada por uma doença que veio evidenciar as fragilidades do Homem e do seu conhecimento, afigura-se pertinente perguntar por que caiu no esquecimento e recebeu de alguns autores a designação de "pandemia esquecida". No entanto, as suas consequências nefastas fizeram-se sentir em todos os países, de diferentes modos e em diversos domínios: fecharam-se escolas, teatros, cinemas e salóes; impuseram-se quarentenas; proibiram-se os ajuntamentos; estabeleceu-se uma etiqueta sanitária e o uso de máscaras; as liberdades individuais foram coartadas; instalou-se a crise económica; a fome chegou a várias regiões do globo.

Após a Segunda Guerra Mundial, com a generalização do estado social, os melhoramentos registados no campo do sanitarismo, da higiene e da alimentação, bem como os progressos no campo da medicina, que permitiram a diminuição da incidência de várias doenças, como a varíola, a tuberculose ou a difteria, o tempo das epidemias parece ter desaparecido das sociedades ocidentais. Todavia, uma nova 
doença alarma as comunidades, reclamando um grande número de vítimas: a poliomielite (Harrison, 2009, p. 167).

Em 1957, surge a chamada gripe asiática, uma das três pandemias do século XX. Com origem provável em Vladivostok, na Rússia, terá começado na China e causado cerca de dois milhôes de mortos, sobretudo crianças e idosos. Portugal não escapou aos seus efeitos. Na década seguinte, em 1968, aparece a gripe de Hong Kong, que terá matado um milhão de pessoas em todo o mundo, incluindo no continente europeu. Já na década de 70, mais precisamente em 1977, ocorreu em Hong Kong o primeiro surto de gripe das aves, que foi eficazmente controlado através do abate em massa de 1,5 milhões de aves domésticas.

Atualmente, pela elevada mortalidade, uma outra enfermidade, associada ao continente africano, preocupa a humanidade: o ébola. Desde os anos 70 do século passado, que ataca algumas regiốes de África. Já nos anos 90, teve lugar uma nova epidemia no Zaire. Desde então, escasseiam as notícias sobre a doença, embora não tenha desaparecido, pois os surtos continuaram com alguma frequência, alguns já no século XXI.

Ainda no século XX, o mundo é confrontado com novos vírus e novas epidemias. Na década de 80, aparece o HIV/SIDA, que se considera ter resultado da mutação de um vírus existente no macaco africano, sendo reconhecida a sua presença na natureza já no século XIX. Aliás, os primeiros casos da doença remontam à década de 60 , no continente africano. Inicialmente associada à comunidade homossexual e aos toxicodependentes, tornou-se motivo de estigmatização. Nos Estados Unidos, por exemplo, adquiriu também uma conotação racial, ao ser atribuída aos imigrantes haitianos a responsabilidade pela sua introdução no país (Harrison, 2009). Fruto da revolução sexual do século XX, a doença rapidamente se propagou entre os heterossexuais. A partir daqui, a maioria dos países apostou na educação sexual e em campanhas de sensibilização com o objetivo de corrigir comportamentos. Nos inícios do século XXI, calculava-se que havia 35 milhóes de pessoas portadoras do vírus. Desde o seu aparecimento, já causou a morte de mais de 20 milhões de pessoas.

De facto, as doenças e as epidemias dos séculos XX e XXI precisam de ser refletidas e contextualizadas. Nesta reflexão, notamos que algumas enfermidades 
adquirem hoje maior relevo e a sua ocorrência é potenciada, nomeadamente, pelo paradigma consumista e pelo sedentarismo, caso das doenças cardiovasculares, enquanto outras resultam da procura desesperada pela competitividade e do questionamento do Estado Social, como refere Ramonet (2002). A este propósito, tome-se como exemplo maior a doença das "vacas loucas", que este autor atribui às políticas liberais de Margaret Thatcher.

Como já tivemos oportunidade de referir, o Homem concorre para o surgimento de novas moléstias e para a sua propagação, através das ações sobre os seus iguais e sobre a natureza. Disso são exemplo as doenças infeciosas que continuam a matar e, decerto, continuarão a matar no futuro, em resultado das alterações climáticas (malária); do aquecimento global, que está a ter impacto em doenças como a dengue e a febre-amarela (Ingar Palmlund, 2012); de catástrofes naturais, que acarretam consequências sanitárias (cólera); da desertificação e da falta de terra arável, que agravam as condições de vida das populaçóes e ao aumento das desigualdades sociais.

Ao invadir a natureza, o homem contacta com animais selvagens, favorecendo a transferência de agentes infeciosos, que podem sofrer mutações ao infetar outras espécies, incluindo a humana. Este avanço é promovido por vários fatores: o progresso e os interesses económicos, que destroem florestas tropicais; o crescimento populacional e urbano; o desenvolvimento e a diversificação do turismo, nomeadamente do ecoturismo; a caça desregrada; os hábitos alimentares de certos povos, que incluem o consumo de animais selvagens.

Note-se, todavia, que a pobreza e as profundas desigualdades sociais também continuam a facilitar a propagação de certas doenças, como a tuberculose, a malária e a febre-amarela, e a permitir que a mesma enfermidade, caso do HIV/SIDA, cause mais ou menos mortos, consoante os países e os continentes. Atualmente, as disparidades entre países tornam-se evidentes no combate às epidemias, e mostram a necessidade de apostar na cooperação e no desenvolvimento de açóes internacionais, que tiveram sucesso no passado, de que é exemplo a erradicação da varíola.

No tempo presente, a humanidade já experienciou três epidemias causadas por coronavírus. A primeira, em 2002, a Síndrome Respiratória Aguda Grave (SARS), que 
teve origem na China, causou cerca de oito mil vítimas e encontra-se erradicada. $\mathrm{O}$ surto terá começado num mercado de animais, onde se vendiam civetas, animais que se julga terem sido infetados por morcegos. Por sua vez, a epidemia de Síndrome Respiratória do Médio Oriente (MERS) surgiu no Médio Oriente, em 2012, e ainda não está extinta. Considera-se o dromedário a fonte primária de infeção, mas é desconhecida a forma de transmissão do vírus para os seres humanos. Quanto ao último surto, de COVID-19, a sua análise carece, obviamente, de algum distanciamento para aclarar algumas das incertezas que envolvem esta pandemia.

\section{CONCLUSÃO}

Ao longo da sua existência, a Humanidade passou por diversas epidemias, nas quais é visível a mão humana. Apesar do incremento dos estudos sobre esta temática, ainda persistem algumas incertezas, sobretudo quanto mais recuamos no tempo e as fontes escasseiam, embora essa dificuldade possa ser resolvida através de investigações pluridisciplinares. A única certeza que podemos ter é que novas pandemias irão aparecer no futuro e que nada nos garante que serão menos mortíferas. Num mundo cada vez mais global, a facilidade e o crescimento exponencial da movimentação de pessoas e bens, as migraçôes e as alterações climáticas estão a provocar desequilíbrios na relação entre o Homem e o meio, pondo em causa a harmonia ecológica.

A História evidencia que a ocorrência de surtos epidémicos, com maior ou menor dimensão, teve consequências que se fizeram sentir de modos e em planos diversos. Assim, descobrimos, por exemplo, o desenvolvimento de políticas opressivas e totalitárias com o pretexto de prevenir ou combater as doenças; a antecipação do fim de modelos económicos, políticos e sociais; a emergência de comportamentos xenófobos e racistas, na tentativa de encontrar um "bode expiatório"; o aumento dos números da pobreza e da exclusão social. Todavia, pela sua dimensão catastrófica, também são demonstradores da capacidade de resposta da sociedade e das suas instituiçóes, da vontade de ajudar quem mais precisa, bem visíveis, por exemplo, no surgimento de organizações solidárias e do crescimento do voluntariado. 
Assim, no presente, tal como no passado, temos de atender aos contextos para analisar as epidemias. Nesse olhar para trás, ao longo dos séculos, descobrimos algumas continuidades discursivas e, no que respeita às medidas tomadas nos dias de hoje, constatamos que, por vezes, só mudam as palavras, além, claro está, das circunstâncias.

Apesar da sua frequência, que procurámos evidenciar, as epidemias parecem teimar em cair no esquecimento da História, escusando-se a sociedade a guardar memória da sua ocorrência. Urge questionar este esquecimento e esta falta de memória... Para recordar eventos traumáticos, como as guerras, reservam-se datas nos calendários, escrevem-se livros e erigem-se estátuas, mas o mesmo não sucede com as epidemias, que, apesar dos milhões de vítimas e dos efeitos colaterais que se prologaram no tempo, são eventos que as sociedades querem ou deixam esquecer...

\section{BIBLIOGRAFIA}

Almeida, M. (2012). A epidemia de cólera de 1853-1856 na imprensa portuguesa. História, Ciências, Saúde Manguinhos, 18 (4), 1057-1071.

Berridge, V. \& Gorsky, M. (2012). Environment, Health and History. London: Palgrave Macmillan.

Beveridge, W. I. B., (1991). The Chronicle of Influenza Epidemics. History and Philiosophy of the Life Sicences, $13(2), 223-234$.

Cohn, S. (2018). Epidemics: Hate and Compassion from the plague of Athens to AIDS. Oxford: Oxford University Press.

Costa, C. (1920). Estudo da gripe epidémica. Porto: Tip. a vapor da Enciclopedia Portuguesa.

Crosby, A. (2003). America's Forgotten Pandemic. New York: Cambridge University Press.

Crosby, A. (2005). Ecological Imperialism. (second edition). Cambridge. Cambridge University Press.

Esteves, A. (2020). A pneumónica em Portugal: a construção da memória. (no prelo).

Esteves, A. (2019). A pneumónica na Imprensa do Distrito de Viana do Castelo. In H. da Silva; R. M. Pereira; F. Bandeira (Coords.), Centenário da Gripe Pneumónica (87-108). Lisboa: IGAS.

Ferreira, F. A. G. (2015). Sistemas de saúde e o seu funcionamento. História da saúde e dos serviços de saúde em Portugal. Lisboa: Fundação Calouste Gulbenkian.

Garcia Ferrero, S. (2018). La gripe de 1889-1890 em Madrid (Tese de doutoramento não publicada). Universidade Complutense, Madrid. 
Lindemann, M. (2002). Medicina e Sociedade no Inicio da Idade Moderna-Novas abordagens da história europeia. Lisboa, Editora Replicação.

Kohn, G. C. (1995). The Wordsworth Encyclopedia of Plague and Pestilence. New York: Facts on File.

Palmlund, I. (2012). The impacts on human health and environment of global climate change: a review of international politics. In V. Berridge \& M. Gorsky (Eds.) Environment, Health and History (244-269). London: Palgrave Macmillan.

Harrison, M. (2009). Disease and the Modern World. 1500 to the present day. Cambridge: Polity Press.

Hays, J. N. (2009). The Burdens of disease. Epidemics and Human response in western history (Revised Edition). New Brunswick: Rutgers University Press.

Oxford, J. (2000). Influenza A pandemics of the 20th century with special reference to 1918; virology, pathology and epidemiology. Medical Virology, 10, 119-133.

Ramonet, I. (2002). Guerras do Século XXI. Novos medos, novas ameaças. Porto: Campo das Letras.

Spinney, L. (2018). El jinete pálido. 1918: la epidemia que cambió el mundo. Barcelona: Editorial Planeta.

Soares, A. (1892). Gripe ou Influenza. Porto: Typographia de Pereira e Cunha.

Stearns, S. \& Koella, J. (2010). Evolution in Health and Disease. Oxford: Oxford University Press.

Snowden, F. M. (2020). Epidemics and Society. From the black death to the present. Yale: Yale University Press.

Weindling, P. (2011). Epidemics and genocide in Eastern Europe, 1890-1945. Oxford: Oxford University Press. 